\title{
NEUROSCIENCE APPLIED TO LEARNING ALPHABETIC PRINCIPLES: NEW PROPOSALS
}

\author{
Leonor Scliar-Cabral \\ Professor Emeritus- Universidade Federal de Santa Catarina
}

\begin{abstract}
This study reviews recent data on functional illiteracy and advances on neuroscience about the reading process. Alarming figures on functional illiteracy will be presented with examples of UK and Brazil. Empirical evidences brought by neuroscience prove the neuropsychological basis constructs, namely invariance already claimed by modern linguistics. However, emphasis will be given to the psychological reality of letters' feature invariance, demonstrated by various experiments which had been recently run by neuroscientists. Two types of invariance are shown, the spatial and the font invariance, exemplified by a description of invariant features of the Roman alphabet. We then cite the major difficulties faced at by beginning readers, namely, how to dismember the chain speech into words (separated in the written space by blanks) and the syllable into its units, in order to link them to their correspondent graphemes (composed by one or more letters). In addition, one of the major difficulties is how to teach neurons to dissymmetrize the letter features. Neuroscience conclusions from experiments about the reading process demonstrate that neurons of the occipito-temporal ventral region of the left hemisphere must be recycled in order
\end{abstract}

\begin{tabular}{|l|l|l|l|l|}
\hline Ilha do Desterro & Florianópolis & $n^{\circ} 63$ & p. 187- 211 & jul/dez 2012 \\
\hline
\end{tabular}


to learn how to recognize the written word. Altogether with the results obtained on a well succeeded experience run by the program Early Intervention Initiative (EII) and by an experiment run in a Florianopolis school, in 2012, they give support to the strategies to prevent functional illiteracy.

Keywords: reading; processing; neurons recycling; neuroscience; functional illiteracy.

\section{Data on functional illiteracy}

Among the 31 countries examined by OECD (2009 edition), Finland (548.2 points) presented the better mean score on the scientific literacy scale, followed by Japan (547.6) while Mexico (the only Latin American country) occupied the worst position (404.9 points). Confirming Finland scores, in 2003, only $0.3 \%$ of girls were identified as very poor readers at age 15 .

Nevertheless, attending school and even finishing elementary school do not guarantee that the person can understand, use and reflect on written texts, in order to achieve her/his goals, to develop her/his knowledge and potential and to participate in society.

The UK government's Department for Education reported in 2006 that $47 \%$ of school children left school at age 16 without having achieved a basic level in functional mathematics, and $42 \%$ failed to achieve a basic level in functional English (Education Guardian, 2007). Every year 100.000 pupils leave school functionally illiterate, in the UK.

Even though the literacy rate may be high, it does not say anything about functional illiteracy. For instance, "While the literacy rate in the United States of America is very high (99\%)" ..."new statistics says that at present there are about 30 million functionally illiterate 
people in the USA and the numbers are growing." (Civilliberties, 2007).

In Brazil, the situation of functional illiteracy continues to be very worrying: according to the 2009 edition of INAF (National Institute of Functional Alphabetism), the most important agency on the subject in the country, only $25 \%$ of Brazilians from 15 to 64 years old completely master reading and writing in Brazil.

It is necessary to find out the causes of this problem, to call upon all the adequate specialists, including applied psycholinguists to solve it. One of the strategies may be looking at the measures adopted by institutions in places where figures of functional illiterates were very high to bring them down.

\subsection{The Early Intervention Initiative (EII) program}

We focus on the Early Intervention Initiative (EII) program, initially developed by the Scottish Executive Education Department in 1997 and implemented by the West Dunbartonshire Council (West Dunbartonshire Council, 2007). They received the prestigious award given by the Municipal Journal for the best achievement in the field of children's care in the UK.

The program started in 1997 with a goal to be met in ten years: eradicating pupils' functional illiteracy. The assistance of the psychologist Tommy MacKay was fundamental. In 1997, only 5\% of primary school children obtained "very high" scores on word reading; under the benefits of the program, in 2007, the figure went up to $45 \%$. The reversion of the problem may also be seen in the fact that in $199711 \%$ of children at the second grade of primary school presented low scores, while in 2007 the figure went down to $1 \%$. In 2001, before the Program could show its effect on students entering 
the secondary school, one among three of those students (28\%) was a functional illiterate: after attending seven years of primary school, her/his level was equivalent to a child nine and a half years old. In August 2005, as a result of the program, only $6 \%$ of those students were still functional illiterates, a figure that the Early Intervention Initiative eliminated by November 2007.

Because of space limitations, we will summarize the main factors that guided the program: developing language awareness at preschool through synthetic phonics and the multi-sensorial approach, with pedagogical material based on research (Lloyd, Wernham \& Jolly, 1993); 10-strand intervention activities, featuring a team of specially trained teachers; continuous assessment and monitoring; extra time for reading in the curriculum; home support for parents and care-givers and the fostering of a "literacy environment" in the community (Education Guardian, 2007).

Since the program began, 30.903 students were tested individually, 29.906, in groups, summing up 60.809 students. Children who did not attain satisfactory levels in learning reading, writing and mathematics were accompanied individually through the program Toe By Toe by specialists till they could overcome their difficulties.

It must be emphasized the policy of the Council administration which had invested in the project: eradicating functional illiteracy in ten years, more precisely, by November 2007, asking specialists as consultants to help it. As already mentioned, the project considered the family and community involvement important and much work was done for supplying the so-called hide curriculum.

The effectiveness of such policy in eradicating the functional illiteracy in the UK is confirmed by Her Majesty's Chief Inspector's, Christine Gilbert's comments in the annual report (Gilbert, 2007, p. 2): 
The final report, published in 2006, drew attention to the fundamental importance of developing children's spoken language. It also made a number of key recommendations for schools, about teaching phonics. In particular, it recommended that systematic phonic work should be taught discretely; in other words, teachers should allocate regular time each day to make sure that children acquire the knowledge, skills and understanding to enable them to decode (to read) and encode (to write/spell) print. It also recommended that high quality phonic work should be the prime approach in teaching children how to read, so that they could move swiftly from 'learning to read' to 'reading to learn'.

\subsection{Reflections about the Early Intervention Initiative (EII) program}

The repercussions of the Early Intervention Initiative (EII) program may be inferred by the fact that "A number of other schools have requested information on the project and some clusters of primary schools have decided to adopt the approach. The project director spoke at an international conference on Language Awareness in Schools in Le Mans in July 2006 and also at the Association for Language Learning Conference in Oxford in March 2007" (ASCL, 2006).

Since many projects for developing literacy showed such poor results, one of the first tendencies is copying without any reflection or adaptation to different scenarios what worked so well in other places. It is evident that some measures are indisputable, like the policy of asking for the help of specialists in the learning-teaching of reading and writing to advise pre and primary school educators as well as the respective pedagogical material writers. Only countries whose priority was education, preparing their teachers and adopting 
materials and methods based on up-to-day scientific research, obtained satisfactory results in reading and writing abilities.

This implies the presence not only of highly specialized educators and psychologists, but also of linguists, psycholinguists, neuroscientists and speech therapists, who take care of the curricula reformulation, of the long term staff education, of the classroom activities, of the pedagogical material and of the remediation of students who have difficulties in learning reading and writing.

Teachers' comprehension of the scientific fundamentals of phonics, for example, inhibit the mechanic and inadequate exercises ministration, which would cause the inverse effect to the desired one. Indeed, the primordial reason of phonics is that the basic unit of the alphabetic systems, namely, the graphemes (constituted by one or more letters), represent one phoneme (sound classes whose function is to contrast meanings). Nevertheless, this goes against the individual's perception of the speech chain before being alphabetized, since the speech chain is perceived as a continuum and this is the main obstacle in learning reading and writing in the alphabetic systems. Therefore, a systematic work must be carried out to help the learner in her/his efforts to rebuild in a conscious way her/his perception of the speech chain for dismembering the syllable into its constituents.

\section{Neuroscience evidences}

Neuroscience findings about the reading process help us to understand the initial difficulties children are faced with when trying to learn how to read. Although any normal baby is compulsorily guided to acquire the sociolinguistic oral variety which he/she is exposed to in order to survive, human neurons are not genetically programmed for learning writing systems. As far as modern man, 
living 140.000 years ago in Africa, it is attested that the number of neurons and the cerebral organization, namely the pre-frontal cortex underwent an enormous expansion (Changeux, 2012). Throwing stones with the right hand for hunting shows that the left hemisphere was dominant, consequently, that specialization was already settled, including language.

The human species is characterized by a bio-psychological apparatus which allows constructing material and spiritual culture and by neurons plasticity capable of learning new features: under the pressure of various socio-economic needs, men invented new tools and techniques which did not cause genetic changes but epigenetic ones, hence the first imply a longer time if compared with the last ones which were caused by new techniques.

This happened with writing systems: the proto-cuneiform (Michailowski, 1996: 33) and the Egyptian script tradition, which included the hieroglyphs (Ritner, 1996: 73) known as the oldest writing systems in the world, were invented at the end of the fourth millennium B.C.E. Even the writing system evolution demonstrates that what took place was not a genetic change on the genes which process natural languages, but a growing adaptation of the neural circuits on the occipito-temporal ventral region of the brain for the recognition of written words (Dehaene, 2012).

If we compare the period when natural languages emerged with that when the first writing systems are attested, there is an enormous chronological distance. It raises important conclusions to understand the reading processes and the learning process involved, even more crucial in the case of the alphabetic systems: they derived from the proto-Sinaitic script, whose earliest manifestation, around 1400 B.C.E., appears on a small sandstone sphinx dedicated to the goddess Hathor (recent research reveals the existence of older examples of a 
similar script, discovered in central Egypt and dating from around 1800 B.C.E. (Scliar-Cabral, 2010: 147).

The most important conclusion is that the writing systems are not spontaneously and compulsorily acquired, but they occur in a systematic context of learning, namely at school.

Neuroscience uses three main techniques at the experimental setting: Magnetic resonance imaging (fMRI), electroencephalography (EEG), and the most efficient for measuring the reading process, the magneto-encephalography (MEG).

Some empirical evidences obtained from the experimental setting only confirm already known principles such as that the primary regions process the gross signals, independently of hemispheric specialization: in the case of the luminous signal, the central occipital region. This first processing takes almost $50 \mathrm{~ms}$. What is new, is accompanying on line, how the output of this first processing is sent compulsorily to the specialized region for reading, the occipito-temporal ventral region of the left hemisphere, if the subject had learnt the written code, independently of the system (alphabetic or logographic). Experiments conducted by Dehaene and colleagues (2002) demonstrated that the left occipito-temporal ventral region is illuminated when subjects are submitted to written words, but not when the same words are only listened. It must be pointed out that the occipito-temporal ventral region may also process faces, objects and instruments, but only some parts of the left occipito-temporal ventral region prefer the recognition of written words, while the right contra-lateral region prefers the recognition of faces (Tarkiainen and cols., 2002). 


\subsection{Processing letter invariance}

Important empirical evidence brought by neuroscience confirms processing letter invariance, which means "the ability to rapidly build up an abstract representation of letter strings invariant for irrelevant parameters such as font, case, size or location" (Qiao et al., 2010, p. 1787).

The first one is the spatial invariance. It is very well known that the visual projections are crossed: words presented to the left side of the screen are projected to the right half of each eye retina from where the information is sent to the right hemisphere. The reverse is true if words are presented to the right side of the screen. The fIRM technique demonstrates that this unilateral processing on the region V4 lasts almost 160 or 170 milliseconds. Suddenly, the output converges to the left occipito-temporal ventral region, no matter if the stimuli were presented at the right or at the left side of the screen. This is possible because the connection between the two hemispheres is mediated by the corpus callosum; consequently, if a patient suffers a vascular lesion there, he will be impeded of recognizing the words presented to the left side of the screen, a syndrome called hemi-alexia.

A lot of experiments showed another type of invariance, the font invariance: the neurons of the left occipito-temporal ventral region, after being recycled, have the ability of recognizing one letter as the same despite its multiple variants. It does not matter if the font is in UPPER CASE, lower case, bold, italic, underlined, or handwriting. Our explanation for this ability comes from the concept of phoneme, which is the fundamental stone of contemporary linguistics, namely, the functionalist approach: the phoneme has a distinctive function, although without meaning, its function is distinguishing meaning. The same is true with letters: one or more letters constitute the 
graphemes linked to their sonorous values (the phonemes), both with the function of distinguishing meaning. Indeed, the evidences got by Polk and Farah (2002) favored the hypothesis of an abstract, not perceptual word-form area.

The region which specifically processes the written material is called left occipito-temporal ventral region. This means that graphemes, after their visual identification, are obligatorily linked to phonemes in this process. In addition, you can observe the many bidirectional arrows that project to all regions where language is processed, including the region where meaning is processed.

Polk and Farah's hypothesis was confirmed by Dehaene and colleagues' (2002) experiment presenting (29 milliseconds) subliminally the first word: the effect on the target word was the same, no matter if both were written in the same font or not: there is a reduction of activity in the left occipito-temporal ventral region. It is interesting to observe that this effect is not observable in the primary visual region, since it is sensitive to the changes of fonts. Only the left occipito-temporal ventral region operates with the font invariance, that is, with more abstract constructs, which are crucial for attributing the same values to letters that in different fonts do not share any feature, as for instance, $\mathbf{A}$ and $\mathbf{a}, \mathbf{G}$ and $\mathbf{g}, \mathbf{M}$ and $\mathbf{m}$.

If the global method was right, the written word would be recognized through its configuration which is exactly what the right hemisphere does: it recognizes FAIR and fair as different (Dehaene et cols., 2004). The same is true with children who did not learn the principles of the alphabetic system and only recognize logotypes like Goca Cola: only the region on the right hemisphere is illuminated during experiments and not the left occipito-temporal ventral region.

Evidence brought up by neuroscience experiments is that the left occipito-temporal ventral region prefers letter chains well formed 
over chains that disobey the graphotactic rules of a given language. This proves that this knowledge is not innate: neurons belonging to the region specialized for recognizing written words must be recycled for learning the specific system. What is also remarkable is that these recent experiments have put an end to the myth that Chinese was a written language only processed by the right hemisphere. Experiments show that reading Mandarin activates preferably the same left occipito-temporal ventral region, with almost the same properties observed while the subjects were reading alphabetic systems. The same is true when subjects are reading logographic kanji or syllabic kana systems (Nakamura et cols., 2005), probably because both respective visual units converge to the same phonemic representation.

If the subject did not learn the written code, the illuminated areas will be those that recognize configurationally the signal.

Recent experiments conducted by Qiao et al. (2010, p. 1786) demonstrated that "Expert readers exhibit a remarkable ability to recognize handwriting, in spite of enormous variability in character shape - a competence whose cerebral underpinnings are unknown". Briefly resuming, the experimenters used behavioral subliminal repetition and fMRI priming to study the areas involved in invariant handwritten word recognition. For instance, the prime word was printed (e.g. PIANO) while the target was handwritten (e.g. piano) and vice-versa.

Six sets of 40 French nouns of high and low frequency, 4-, 6-, and 8-letter in length, were selected from the www.lexique.org., and then presented to 21 participants who were asked to copy each one in their usual handwriting. Six styles were selected and the words were scanned. Words generated by a pseudo manuscript computer font and by common Arial font were added. Further, an average width of the 
letters was obtained. Eight sets of 60 words, constituting a total of 480 words, combining frequency $x$ length were shown to 16 participants to read them aloud. "Responses triggered the presentation of the next word. Latencies were measured with a voice-key and responses were recorded for subsequent scoring" (Qiao et al., 2010, p. 1787). Half of words referred to natural objects, and the other half to artifacts.

In a second fMRI experiment, each trial consisted of the sequence of $4000 \mathrm{~ms}$ fixations across, a $50 \mathrm{~ms}$ mask, a $50 \mathrm{~ms}$ prime word, a 200 ms target word, a $1100 \mathrm{~ms}$ fixation across and a $16 \mathrm{~ms}$ blank screen. The $50 \mathrm{~ms}$ prime word guaranteed that it would not be consciously perceived.

There were six types of fMRI trials:

PRIME

Printed upper case Printed upper case Printed upper case printed lower case easy handwriting difficult handwriting
ALLIANCE

ALLIANCE ALLIANCE alliance alliance

\section{alliance}

printed lower case easy handwriting difficult handwriting Printed upper case Printed upper case Printed upper case
TARGET alliance $\quad \mathrm{Pp}$ alliance $\mathrm{Pe}$

alliance $\mathrm{Pd}$ ALLIANCE pP ALLIANCE eP ALLIANCE dP

Table 1. fMRI trials.

Primes and targets never shared the same case (upper and lower), to avoid the bias of repetition of low-level visual features. The aim was to attribute the prime effect to an invariant representation of abstract letter identities.

Primes and targets were the same word on half of the trials and semantically different (natural objects opposed to artifacts) on the other half. The list of 48 words was divided in two equivalent sets of 24 words, one with conditions Pp, Pe and Pd for half of subjects and the other with conditions $\mathrm{pP}, \mathrm{eP}$ and $\mathrm{dP}$ for the other half of subjects. A 13th category with blank screens was used as a baseline. 
Results showed that "Clearly the same areas were activated irrespective of style, with a strongly left-predominant maximum in the Visual Word Form area. The perception of the most demanding targets, i. e., difficult handwritten words, boosted ventral activations precisely at the main peak of the Visual Word Form area" (Qiao et al., 2010, pp. 1796), namely in its more anterior sections. The predominance of the left occipito-temporal ventral region for the recognition of written words, including handwritten ones, is confirmed by what happens with pure alexic patients.

Nevertheless, when the surface cues considerably deviate from the features which differentiate one letter from the others, as is the case with the difficult style of some handwriting, the automatic tuning into invariance is delayed, being preceded by necessary attentive and topdown processes, calling the intervention of parietal-frontal attentive networks as well as reading pathways under the control of dorsal cortex. This was exactly what happened in Quio et al's experiment.

The delayed response to difficult handwritten style was demonstrated in the first experiment by a drastic difference in mean reading time. In the second experiment, there was no positive effects caused by difficult handwritten primes on printed upper case targets processing because $50 \mathrm{~ms}$ time of subliminal exposure is not enough for calling attentive and top-down processes, needed for difficult handwritten words decoding: subliminal exposure is efficient only for automatic bottom-up processing: "if the processing of handwritten words requires attention, then they might not yield significant repetition effects when used as subliminal primes" (Quio et al., 2010). 


\subsection{Neurons recycling}

Neuroscience demonstrated another major difficulty, namely, that neurons in mammals are programmed to process the visual signal symmetrically: for surviving it is economically efficient to disregard the differences that eventually may exist between the direction of cues to the left and to the right side, to the bottom and to bellow, for perceiving any object at sight.

This innate property was experimentally demonstrated by Verhaeghe and Kolinsky (1991): the identification of objects does not depend upon the different spaces they occupy, or if they appear in one position or another, like a chair turned to the left, to the right, or even upside down.

But this is not the case for the recognition of letters: neurons must learn how to recognize these differences, which are absolutely pertinent for learning how to read. The need is dramatic in the case of mirroring letters like $\mathbf{b} / \mathbf{d}, \mathbf{p} / \mathbf{q}, \mathbf{b} / \mathbf{p}, \mathbf{d} / \mathbf{q}, \mathbf{n} / \mathbf{u}, \mathbf{a} / \mathbf{e}$. Thanks to the human neuron plasticity, it is possible for them to be recycled (Dehane, 2012), if the context of teaching and learning is adequate, otherwise students will continue to show their initial difficulties being frequently labeled as dyslexics. Dehaene termed neuronal recycling this ability of neuron learning, resulting from "[...] the partial or total invasion of cortical territories initially assigned to a different function, by a new cultural object". In a recent study, Dehaene et al. (2010) demonstrate the cerebral area where this learning takes place, namely, the left fusiform visual word form area: on the course of learning how to read, the neurons located in this region must learn how to block the brain mechanisms underlying mirror generalization in favor of recognizing relevant differences among features directions, when processing written words. Interesting enough, this ability must 
cohabit with the visual neurons mirror generalization for recognizing other images. Dehaene and colleagues

used fast behavioral and fMRI repetition priming to probe the brain mechanisms underlying mirror generalization and its absence for words in adult readers. In two groups of French and Japanese readers, we show that the left fusiform visual word form area, a major site of learning during reading acquisition, simultaneously shows a maximal effect of mirror priming for pictures and an absence of mirror priming for words. Thus, learning to read recruits an area which possesses a property of mirror invariance, seemingly present in all primates, which is deleterious for letter recognition and may explain children's transient mirror errors.

\subsection{Letter feature invariance}

The following are the invariant features used in printed fonts (some letters are formed by only one feature, for instance, capital letters $\mathbf{I}, \mathbf{C}$ and $\mathbf{O}$ and small letters $\mathbf{I}, \mathbf{C}$ and $\mathbf{O}$ ). The most basic features that form the letters are straight lines and curves, articulated into smaller differences, which will be described:

- position of the straight line: vertical, horizontal or inclined. For instance, the letter $\mathbf{E}$ shows a vertical straight line and three horizontal ones, while letter $\mathbf{V}$ shows two inclined straight lines;

- size of the straight line: it can be noticed that the horizontal straight lines are always shorter than the vertical ones (both preserving each size in the same font). Compare, for instance, those sizes in the following letters: $\mathbf{E}, \mathbf{F}, \mathbf{H}, \mathbf{L}$ and $\mathbf{T}$. 
- relations among features in the same letter: relations may be among straight lines (in different positions), among curves or mixed, varying the place where the smaller straight lines are placed in relation to the main axis and how many they are. Therefore, the sole difference between $\mathbf{E}$ and $\mathbf{F}$ consists in the fact that $\mathbf{E}$ has one more straight line at the bottom and both are different from $\mathbf{L}$ because the last letter has only one horizontal straight line at the bottom. In the case of the letter $\mathbf{T}$, the vertical straight line touches at the top in the middle of the horizontal straight line, while in the case of $\mathbf{H}$, the two parallel vertical straight lines are linked at their middle by an horizontal one. In conclusion, those five capital letters articulate exactly two features, being the sole difference the way they relate and how many times they are repeated: L T F E H.

An example of relation between curves is the letter $\mathbf{S}$ (both capital and small ones), where the curve $\mathbf{C}$ is mirrored top down and right to left. Besides this difficulty, the grapheme presents additional ones since it may represent different phonemic values.

The most common are the mixed relations. A small curve articulated with a straight vertical line, at the bottom or top, at right or left side, combined with a semicircle, repeated or cut by a very small horizontal straight line makes the differences among the following letters: $\mathbf{J}, \mathbf{a}, \mathbf{f}, \mathbf{g}, \mathbf{h}, \mathbf{j}, \mathbf{m}, \mathbf{n}, \mathbf{r}, \mathbf{t}$ and $\mathbf{u}$.

- direction towards right or left side, towards bottom or top (mirroring). This last feature is the most difficult one, since the perception of this difference is against the natural neurons' disposition to find symmetry on the visual cues. This difference 
is the sole one between the following pairs: $\mathbf{b} / \mathbf{d}, \mathbf{p} / \mathbf{q}, \mathbf{M} / \mathbf{W}, \mathbf{n} / \mathbf{u}$, $\mathbf{b} / \mathbf{p}, \mathbf{d} / \mathbf{q}$ and, approximately, between $\mathbf{A} / \mathbf{V}, \mathbf{S} / \mathbf{Z}, \mathbf{a} / \mathbf{e}, \mathbf{s} / \mathbf{z}$ and $\mathbf{f} / \mathbf{j}$.

\section{Difficulties for learning how to read}

\subsection{Differences between processing the speech chain and processing the written word}

Since the conference on The Relationship between Speech and Learning to Read (RSLR), sponsored by the Growth and Development Branch of the Institute of Child Health and Human Development (NICHD), held at Belmont, USA, on May 16, 1971 (Kavanagh \& Mattingly, 1972), there was an agreement among the participants on what Jenkins and Liberman (1972, p.1) stated as the starting point of the conference, namely, the shocking contrast between the difficulties in perceiving the speech chain and reading.

The first difficulty consists of the fact that, before knowing the principles of the alphabetic system, the child does not perceive the contrasts among the syllable constituent units. Therefore, he/she cannot dismember it. This is absolutely necessary for understanding the principles of the alphabetic systems, since each grapheme (one of more letters) represents a phoneme and not a syllable.

When the child enters school, he/she has already internalized the phonological system of his/her sociolinguistic variety. The chains of speech he/she processes show neither pauses between words nor contrasts between segments: by virtue of co-articulation, an overlapping occurs among acoustic cues of the adjacent segments. 
204 Leonor Scliar-Cabral, Neuroscience applied to learning alphabetic...

Since this processing is not conscious, it is inaccessible for the child's inspection. The last one only becomes possible if a kind of language is available for labeling the units and cutting them down, a process known as phonemic awareness. Consequently, an essential differentiation has to be done between unconscious phonemic knowledge for using language by way of declarative memory and phonemic awareness. The first one every native speaker of any sociolinguistic variety has, being spontaneously internalized during language acquisition, while the second one only those that had learnt an alphabetic system can manage.

All evidences demonstrate, on the other hand, that such learning is not easy. I will stress those difficulties examining them on the alphabetic system.

Although both oral and alphabetic systems share some common architectonic properties, i.e., three articulations, the first, combining meaningful units, the second, combining meaningless units, respectively phonemes and graphemes, and the third, articulating phonetic features and letters features, there are deep differences determined by the way the speech chain is perceived and the way the written word occurs.

Those differences oblige that alphabetic systems learning takes place when the learner is already able to use metacognitive and metalinguistic strategies feeding his/her procedural memory, since this learning demands conscious work. The child will have: a) to reorganize the way he/she perceives the speech chain; b) to realign his/her mental lexicon and c) to recycle the vision neurons to recognize one letter's feature differences from the others. All this work has one purpose: to discover the principles of the alphabetic system. 


\subsection{Three major difficulties}

The ability for separating a consonant from a co-articulated vowel develops only when a person becomes proficient in associating a grapheme to a phoneme. Neither illiterates, nor semi-illiterates nor even those that had learnt syllabic or morphemic systems (Morais, 2010; Read et al., 1986) are able to dismember the syllable.

The second difficulty deals with delimiting words, namely unstressed words. Before learning how to read, the child processes the speech chain as a continuum: there are no blanks separating words. The worst is delimiting unstressed words, i. e., clictics, which carry additional problems, since they only represent grammatical meaning, besides always being affected by phonetic changes, as, for example, syllabic reanalysis, i. e., the phenomenon known as closed external juncture or external sandhi. Examples are /'ku.dn/, which relates to two words "could" and "not", in English, /u. zow.'vi.duS/ which relates also to two words "os" (the) and "ouvidos" (ears), in Portuguese and /u.'nuo.mo/ which relates also to two words "un" (a) "uomo" (man) in Italian. This phenomenon blurs the frontiers between words which probably has a repercussion on the form of mental internalized lexical items.

The third difficulty derives from the fact that vision neurons of primates are genetically programmed for disregarding the minimal differences among basic features, namely the differences of direction to right opposed to the left, and of direction to the bottom, opposed to the top. For recognizing one thing as being the same, those differences are disregarded, being symmetrized. It does not matter if a cup is shown with its handle to the right or the left, it will be always recognized as a cup. But this is not the case with letters perception, since, for instance, the three horizontal lines of the capital letter $\mathbf{E}$ 
must be located only on the right side of the vertical line. It is more difficult recognizing the differences between $\mathbf{d}$ and $\mathbf{b}$ or between $\mathbf{q}$ and $\mathbf{p}$, since they depend exclusively on the fact that the first letters of each pair have the semicircle on the left side of the line and the second letters, inversely, have it on the right side of the line, those showing a mirroring horizontal effect. A mirroring vertical effect is shown in the following pairs: $\mathbf{M} / \mathbf{W}, \mathbf{b} / \mathbf{p}, \mathbf{d} / \mathbf{q}, \mathbf{e} / \mathbf{a}$ and $\mathbf{u} / \mathbf{n}$.

This means that for recognizing the letters, neurons of the occipito-temporal ventral region of the left hemisphere must be recycled for perceiving the minimal feature differences among them and this learning will only succeed if one or more letters, the graphemes, are introduced inside words, where they have the function of distinguishing meaning.

In addition, this recycling is quite difficult, because it must coexist with the other vision neurons which disregard those minimal differences. This is the reason why some children persist in their mirroring reading and writing for so long, but this does not mean that they are dyslexic.

\section{The Brazilian experiment}

In 2011, two researchers, Lidiomar José Mascarello and Miriam Maia, under the supervision of Scliar-Cabral, ran an experiment at the school "Centro Educacional Harmonia", in the surroundings of Florianópolis, Southern part of Brazil. The object was to test the reliability of the System Scliar-Cabral of learning the alphabetical principles of Brazilian written language. The theoretical support of the system was presented above. Strategies of the teaching-learning process are guided by three interdependent concepts: 
- recognizing the direction of the features which differentiate one letter from the other;

- mastering the grapheme values, associated to the respective phoneme;

- phonemes and graphemes have the function of distinguishing meaning, therefore, graphemes must be inside words and the later, inside a structured text.

In the beginning, students read aloud only the words the grapheme of which they have learnt: the teacher assists them, completing the reading of the remaining words.

Introducing the graphemes follows a rigorous order, from the simpler ones to the more complex. This means, simplicity of features, correspondent phoneme able to be pronounced alone, value independent of the graphemic context and minimum of allophones in the correspondent phoneme.

16 students constituted the experimental group. 23 students, belonging to the school "Escola Expressão", formed the control group. Tests were applied in both populations, the mean age of which was 6 years old, when the experiment began.

The material consisted of a guide for the teacher (which was discussed with her in seminars), the spelling book (left page with the spelling exercises and right page with a serial story, each chapter centered in the respective grapheme taught) and a collection of games for letter recognition.

The two researchers visited the experimental group each week, giving support to the teacher. At the end of the seventh month, 8 students could read book stories fluently. At the end of the academic 
year, these 8 students could read fluently, 4 were slower and 4 were unable for the following reasons: one child had vision deficit and was not diagnosed on time; one child was absent during 5 months; one child was not 6 years old when classes started (she lived with her grand-mother and did not have family support); the last one only came to school in the second semester.

Report on the comparison with the control population will be the object of another paper.

\section{Concluding remarks}

In this paper, I developed argumentation on how we can apply neuroscience to learning alphabetic principles. I began the paper, showing the alarming figures on functional illiteracy, with examples of UK and Brazil. Then, I presented empirical evidence brought by neuroscience proving the neuropsychological basis constructs, namely invariance already claimed by modern linguistics. Emphasis was given to the psychological reality of letters' feature invariance, demonstrated by various experiments which had been recently run by neuroscientists. Two types of invariance were shown, the spatial and the font invariance, exemplified by a description of invariant features of the Roman alphabet. I explained the initial difficulties children are faced with when trying to learn how to read, namely that, firstly, before knowing the principles of the alphabetic system, the child does not perceive the contrasts among the syllable constituent units; secondly, the difficulty of delimiting words, namely unstressed words and thirdly, the fact that vision neurons of primates are genetically programmed for disregarding the minimal differences among basic features and the differences of direction such as right as opposed to left, and of vertical position, the bottom, as opposed to the top. 
Neuroscience conclusions from experiments about the reading process demonstrate that neurons of the occipito-temporal ventral region of the left hemisphere must be recycled in order to learn how to recognize written words. Altogether with the results obtained on a successful experience run by the Early Intervention Initiative (EII) program and by an experiment run in Florianopolis school, in 2012, they give support to the strategies to prevent functional illiteracy.

\section{References}

ASCL . (2006) . Annual report 2006. <http://www.ascl.org.uk/mainwebsite/ resources/document/annual\%20report\%202006.pdf >. (Access on Oct. $25,2007)$.

Changeux, J.-P. (2012). Prefácio. In: DEHAENE, S. Os neurônios da leitura. Transl. SCLIAR-CABRAL, L. Porto Alegre: Penso.

Civilliberties. The teleconference about functional illiteracy, 2007. $<$ http://civliber. blogs.bftf.org/2007/07/27/ the-teleconference-aboutfunctional-illiteracy/>. (Accessed in Oct. 24, 2007).

Dehaene, S. (2012). Os neurônios da leitura. Transl. SCLIAR-CABRAL, L. Porto Alegre: Penso.

Dehaene, S.; Jobert, A.; Naccache, L.; Ciuciu, P.; Poline, J. B.; Le Bihan, D. \& Cohen, L. (2004). Letter binding and invariant recognition of masked words: Behavioral and neuroimaging evidence. Psychol Sci, 15(5), pp. 307-313.

Dehaene, S., Le Clech, G. Poline, J. B., Le Bihan, D. and Cohen, L. (2002). Cerebral mechanisms of word masking and unconscious repetition priming. Nat. Neurosci, 4(7), 752-758.

Education Guardian. Sounds incredible. The Guardian. Tuesday, July 10, 2007. <http://education. guardian.co.uk/egweekly/ story/0,,2122125, 00. html>. (Accessed in Oct. 24, 2007).

Gilbert, C. Commentary by Her Majesty's Chief Inspector. In: The Annual Report of Her Majesty's Chief Inspector 2006/07. Ofsted, 2007. <http:// live.ofsted.gov.uk/ publications/ annualreport0607/commentary/ page_1.htm>. (Accessed in Oct. 29, 2007). 
INAF (2009). Inaf Brasil 2009 - Indicador de Alfabetismo Funcional: Principais Resultados. <http://www.ibope.com.br/ipm/relatorios/ relatorio_inaf_2009.pdf $>$ (Accessed in March, 17, 2012).

Jenkins, J.J., \& Liberman, A.M. (1972). Background to the conference. In J.F. Kavanaugh \& I.G. Mattingly (eds.), Language by ear and by eye. The relationships between speech and reading. Cambridge, Mass. M.I.T.

Kavanagh, I.J;; Mattingly, I.G. (eds.), (1972). Language by ear and by eye. The relationships between speech and reading. Cambridge, Mass. M.I.T., pp. 1-2.

Lloyd, S., Wernham, S, \& Jolly, C. (1993). Jolly Learning. High Road, Chigwell, Essex: Tailours House.

Michailowski, P. (1996). Mesopotamian cuneiform. In: p. tdaniels; w. bright (eds.), The world's writing systems. New York/Oxford: Oxford Univ. Press, pp. 33-72.

Morais, J. (2010). Flows of information in and between systems of lexical access. In: L. SCLIAR-CABRAL (ed.), Psycholinguistics - Scientific and technological challenges. Porto Alegre: EDIPUCRS.

Nakamura, K., Dehaene, S., Jobert, A., Le Bihan and D. Kouider, S. (2005). Subliminal convergence of Kanji and Kana words: further evidence for functional parcelation of the posterior temporal cortex in visual word perception. J Cogn Neurosci, 17(6), 954-968.

OECD (2009). PISA 2009 Assessment Framework - Key Competencies in Reading, Mathematics and Science. <http://www.oecd.org/document/44/ 0,3343, en_2649_35845621_44455276_1_1_1_1,00.html>. (Accessed in 05/06/2010).

Polk, T. A. and Farah, M. J. (2002). Functional MRI evidence for an abstract, not perceptual word-form area. J Exp Psychol Gen. 131(1), 65-72.

Qiao, E., Vinckier, F., Szwed, M., Naccache, L., Valabregue, R., Dehaene, S. and Cohen, L. (2010). Unconsciously deciphering handwriting: Subliminal invariance for handwritten words in the visual word form area. Neuroimage, 49(2), 1786-99.

Read, C. et al. The ability to manipulate speech sounds on knowing alphabetic reading. Cognition, Special Issue, 24, pp. 31-34, 1986. 
Ritner, R. K. (1996). Egyptian writing. In: P. T. DANIELS; W. BRIGHT (eds.), The world's writing systems. New York/Oxford: Oxford Univ. Press, pp. 72-87.

Scliar-Cabral, L. Sagração do Alfabeto. Trad. Walter C. Costa (esp.); MarieHélène

C. Torres (fr.); Alexis Levitin (ing.)e Naama Silverman Forner (hebr.). São Paulo: Scortecci, 2010.

Tarkiainen, A., Cornelissen, P. L. and Salmelin, R. (2002). Dynamics of visual feature analysis and object-level processing in face versus letterstring perception. Brain, 125 (Pt 5), 1125-1136.

Verhaeghe, A., Kolinsky, R.. (1991). Discriminação entre figuras orientadas em espelho em função do modo de apresentação em adultos escolarizados e adultos iletrados. In: Jornadas de estudo dos processos cognitivos, 1, 1991. Actas... Lisboa: Sociedade Portuguesa de Psicologia, 51-67.

West Dunbartonshire Council. (2007). Literacy initiative wins major award. News Room. 29/07/2007. <http://www.wdcweb.info/ news/ displayarticle. asp?id=12752>. (Accessed in Oct. 24, 2007).

[Received in 02/06/2012. Approved in 15/08/2012] 



\section{Book Reviews}

